\title{
From the high Arctic to the equator: do soil metagenomes differ according to our
} expectations?

Dorsaf Kerfahi ${ }^{1}$, Binu M. Tripathi ${ }^{2}$, Ke Dong ${ }^{1}$, Mincheol Kim ${ }^{2}$, Hyoki Kim ${ }^{3}$, J. W. Ferry Slik ${ }^{4}$, Rusea Go ${ }^{5}$, Jonathan M. Adams ${ }^{6^{*}}$

${ }^{1}$ Department of Biological Sciences, Seoul National University, Gwanak-Gu, Seoul 151-747, Republic of Korea.

${ }^{2}$ Korea Polar Research Institute, 26 Songdomirae-ro, Yeonsu-gu, Incheon 21990, Republic of Korea.

${ }^{3}$ Celemics Inc., 19F, Bldg. A, BYC High city, 131, Gasandigital 1-ro, Geumcheon-gu, Seoul, 15 153-718, Korea.

${ }^{4}$ Faculty of Science, Universiti Brunei Darussalam, Gadong, Brunei Darussalam.

${ }^{5}$ Department of Biology, Faculty of Sciences, Universiti Putra Malaysia, Serdang, Selangor 43400, Malaysia

${ }^{6}$ Division of Agrifood and Environment. School of Water, Energy and Environment. Cranfield University, Bedfordshire MK43 0AL, UK.

*Corresponding author: Jonathan M. Adams,

E-mail: geograph.ecol@gmail.com and j.m.adams@cranfield.ac.uk 


\section{Abstract}

Comparing the functional gene composition of soils at opposite extremes of environmental gradients may allow testing of hypotheses about community and ecosystem function. Here, we were interested in comparing how tropical microbial ecosystems differ from those of polar climates. We sampled several sites in the equatorial rainforest of Malaysia and Brunei, and the high Arctic of Svalbard, Canada and Greenland, comparing the composition and the functional attributes of soil biota between the two extremes of latitude, using shotgun metagenomic Illumina HiSeq2000 sequencing. Based upon 'classical' views of how tropical and higher latitude ecosystems differ, we made a series of predictions as to how various gene function categories would differ in relative abundance between tropical and polar environments. Results showed that in some respects our predictions were correct: the polar samples had higher relative abundance of dormancy related genes, and lower relative abundance of genes associated with respiration, and with metabolism of aromatic compounds. The network complexity of the Arctic was also lower than the tropics. However, in various other respects the pattern was not as predicted: there were no differences in relative abundance of stress response genes, nor in genes associated with secondary metabolism. Conversely, CRISPR genes, phage-related genes, and virulence disease and defense genes, were unexpectedly more abundant in the Arctic, suggesting more intense biotic interaction. Also, eukaryote diversity and bacterial diversity were higher in the Arctic of Svalbard compared to tropical Brunei, which is consistent with what may expected from amplicon studies in terms of the higher $\mathrm{pH}$ of the Svalbard soil. Our results in some respects confirm expectations of how tropical versus polar nature may differ, and in other respects challenge them.

Keywords: Arctic; functional genes; shotgun metagenomics; microbial diversity; tropics. 


\section{Introduction}

Biologists have long been fascinated by the differences between tropical ecosystems and those of higher latitudes. There is a striking gradient in biological diversity in many groups of organisms [1-4], and tropical life forms have often been reported to be more colorful $[5,6]$, better defended [7], yet more often attacked by predators and parasites, and entering into more subtle and specific interactions with other organisms [6, 8-10]. It is suggested that the almost constant climate and the very high productivity of the equatorial tropics result in very stable populations and highly predictable interactions $[6,11,12]$. Certain studies have supported the classical view of how the tropics differ from the high latitudes, concluding that predation, herbivory and mutualism are indeed higher at low latitudes $[8,10]$. However, many other studies on these have found the opposite pattern, for example Anderson et al. [13] found that brood parasitism of the Grey Warbler varied positively with latitude in New Zealand. Others found no significant latitudinal difference, for example Garcia et al. [14] found that seed predation in Juniperus communis did not vary among different regions in Europe. Moles and Ollerton [6] have suggested that for the most part, the classical view of latitudinal differences in niche, community and ecosystem structure is a 'zombie idea', already essentially dead due to an abundance of contrary evidence but continuing to 'feed on the brains' of ecologists. Adding to the uncertainty, there are other aspects of high and low latitude ecology that have not yet been properly compared with respect to classical hypotheses of low and high latitude differences. These include the functional metagenome structure of soil biota, which reflects the totality of the genetic capabilities of the soil organisms present. This is a major gap in understanding, as soil biota represent a major proportion of the Earth's living biomass [15], and perhaps the majority of its biological diversity [16]. 
Most previous studies that have compared soil biota latitudinally have focused on the taxonomy and phylogeny of soil microbial community [17]. There have been few studies of trends in soil metagenomes between different climates and biomes. One previous metagenome study by Tripathi et al. [18] has investigated how the taxonomic and functional characteristics of the soil microbial community differ along a precipitation gradient in Israel, finding a distinct taxonomic and functional microbial community in each precipitation zone. Along the gradient towards greater aridity, there was a decrease in annotated gene functional diversity, with lower abundance of genes related to nutrient cycling such as nitrogen, potassium and sulfur metabolism and higher abundance of genes related to dormancy and sporulation in the driest desert environments. On the basis of lower abundances of genes relating to cell-cell interactions, Tripathi et al. suggested more limited biotic interaction in the most arid environments. In an earlier, pioneering study of metagenomes from different parts of the world, Fierer et al. [19] found several differences in the structure and function of soil microbiome from a range of different biomes around the world - including various desert and non-desert biomes. They noted that Antarctic polar desert soils had the lowest protein functional diversity of those they sampled, based on gene annotations. Fierer et al. [19] also found lower abundances of antibiotic resistance genes in desert soils (including polar desert) compared to non-desert biomes, which they took as an indicator of the decreased selective importance of biotic interactions in desert environments. They also noted that desert environments generally had lower frequencies of genes related to metabolism of aromatic compounds - which they suggested as being due to the lower abundance of plant material. However, in Fierer et al's [19] study there was not a focus in comparing the extremes of polar versus equatorial environments. While incorporating samples from multiple biomes (boreal, temperate, steppe, warm desert and polar desert), at the extremes of latitude it was based on only one sample from a tropical equatorial environment, and six samples from Antarctic polar desert. 
Here, we decided to focus on how the functional characteristics of the soil biota vary between tropical and polar soils, in relation to certain general expectations as to how a tropical ecosystem will differ from a higher latitude one. Comparing two extremes of the range of land environments may more clearly reveal the functional gene differences that tend to be associated with latitudinal differences in climate conditions. Understanding such details of functional gene differences may reveal underlying differences in ecosystem functionality between the tropical and polar regions - differences which would potentially have a range of effects on community structuring, biogeochemical processes, evolution of organisms, and species diversity. Amongst the microbial soil biota, most of the same high level taxa (family level and above) are found in tropical and high latitude/boreal/arctic zones, with much overlap at genus level, and a smaller proportion of overlap at the 'species'/OTU level [20, 21]. At the broad taxonomic level, the differences are mainly in terms of relative abundances, rather than presence/absence. Although the ultimate reasons are of course hard to discern, we assume that in the realm of soil microbial life, very large differences in climate are not as great a functional challenge as they would be for more complex large organisms, and thus relatively few gene changes might allow members of the same microbial taxon - the same genus or even species - to occur in both environments. For example, coping with freezing of tissues may not be too great a barrier for evolutionary adaptation by a relatively simple single-celled organism, but much less likely for a large organism to arrive at by microevolution involving a few gene changes. Differences in relative abundance of the same taxa between the tropical and polar environments might well relate to either differences in the availability of the types of resources that they exploit, the relative abundance of the type of chemical or physical soil microsite in which they tend to occur, or their relative competitive effectiveness under the altered conditions which may narrow down their realized niche and reduce their abundance. 
In this study, we chose multiple sites at the extremes of the latitudinal gradient: equatorial rainforest (Brunei and Malaysia) and polar sites (high Arctic tundra in Svalbard, Cambridge Bay in Canada and Zackenberg in Greenland). Most of what is so far known about the detailed composition of tropical and arctic soil biota is from amplicon sequencing of bacterial [22] and fungal [23] rRNA genes, which are used as an indicator of taxonomic identity. Focusing on these 'barcoding' genes provides no direct indication of genomic functional characteristics: functional differences can only be inferred indirectly from the capabilities of known relatives which have been cultured and studied. In the phenomenally high diversity of soil, most OTUs of microbes have never been cultured, and between closely related OTUs (or even within an OTU) there may be major functional differences in certain key genes (e.g. between litter decomposing and pathogenic forms (Sawana et al 2014) of Burkholderia). If the aim is to deduce the importance of particular functions, and if the resources required for sequencing metagenomes are available, it seems better look for each of these genes directly. Hence, our intention here was to assess the whole metagenome, on the premise that by including the full range of functional genes, it would offer greater insight to the similarities and differences between community and ecosystem functioning of tropical and polar terrestrial environments, which might also ultimately turn out to have implications for understanding evolutionary history and diversity of larger organisms. (REF: Sawana A, Adeolu M, Gupta RS (2014). "Molecular signatures and phylogenomic analysis of the genus Burkholderia: proposal for division of this genus into the emended genus Burkholderia containing pathogenic organisms and a new genus Paraburkholderia gen. nov. harboring environmental species". Front Genet. 5: 429. doi:10.3389/fgene.2014.00429.)

Drawing broadly on the tradition of comparing tropical and high latitude biology in work cited above [6], we made the following general predictions about how the community composition 
and functional ecology of soil biota would differ between the equatorial tropics and the high Arctic:

1) Greater diversity of taxa and gene functions in the tropics. In the tropics, the greater taxonomic diversity of plants, insects and vertebrates may be expected to result in a greater range of materials for decomposition, and a greater range of chemical and physical properties of materials (for example a greater range of secondary compounds, from the wide range of plant taxa contributing to the soil organic matter) [24-29]. This would be expected to result in a greater diversity of microscopic organisms - bacteria, eukaryotes archaea in tropical samples as well as greater richness of gene functions. Fierer et al. [19] noted that in their global survey, polar desert metagenomes had a lower taxonomic diversity than the other biomes they sampled, although Tripathi et al. [18] did not find such a trend in their survey along a precipitation gradient into hot desert.

Also, in the tropics it is to be expected (in the traditions of thinking outlined above [6]) that the very constant climate conditions and primary production allow close co-evolution of soil taxa in terms of mutualism, interference competition, predation and disease (see hypothesis 5 below). This may be expected to bring about a greater diversity of additional sets of genes which further add to the overall functional diversity - for example, antibiotic related genes, and virulence related genes related to specific positive and negative interactions. This general pattern is also foreshadowed by the findings of Tripathi et al. [18] and Fierer et al. [19] of lower functional diversity in more extreme environments.

2) Genes for dormancy will be more common in polar environments. To escape extreme and fluctuating environmental conditions in polar regions, which are often inimical to growth and survival of active cells, we hypothesize that many members of soil microbial communities will enter dormant states until they encounter supportive conditions of active life [30]. In the moist 
equatorial tropics, by contrast, the active growing season is year-round, with temperature and moisture conditions on the rainforest floor nearly always favourable for growth - thus we expected a lower abundance of genes associated with dormancy in the equatorial tropics.

3) Stress response genes will be more common in polar environments. We expected stress response genes to be more common in polar regions, because polar soil organisms are exposed to many intense environmental stresses including extreme cold and freeze-drying, prolonged low temperatures close to freezing, daily freeze-thaw cycles, and prolonged sunlight exposure at the soil surface during summer [31]. None of these factors can be expected to influence the soil biota under closed tropical equatorial rainforest, where light levels are very low and temperatures almost constant. However, paradoxically no such trend was seen by Tripathi et al. (REF) along a precipitation gradient into hot desert,

4) Genes associated with replication and cell division more common in the equatorial tropics. We hypothesized that in the tropical rainforest environment, in moist warm soils under low exposure to UV light beneath the forest canopy - physiological conditions that are almost constantly favourable for rapid growth and cell division [32] - would lead to a greater relative abundance of genes involved in growth/cell division.

5) Genes associated with viruses and anti-virus defenses more common in the equatorial tropics. Population, community and ecosystem ecology has long emphasized the view that in the equatorial tropics - with constant host populations and year round biological activity parasite and disease populations will build up and play a greater role in controlling host populations [12]. This paradigm also relates to the general thinking of ecologists on plant herbivory and defenses [7, 11]. In polar environments, by contrast, there will be frequent population crashes and recovery phases due to seasonal and shorter term environmental fluctuations, and extended periods of host dormancy making them unavailable as hosts. We 
expected that pathogens/predators of bacteria (and other microbes) such as viruses, and viruslike elements, would be more abundant as a part of the soil metagenome in a tropical environment. We also expected that anti-virus defenses, such as CRISPR elements [33] would be relatively more abundant in the tropical metagenome, due to heavier selection pressure to resist cell invasion by viruses.

6) Genes associated with metabolism of aromatic compounds will be relatively more abundant in the equatorial tropics. There is a widespread and long-standing view that secondary compounds, including aromatic compounds, are more abundant in the equatorial tropics than in higher latitude environments $[7,34]$. This is because in the tropics, stable growth conditions resulting from year round biological activity, near constant temperatures and moisture availability results in higher plant biomass and diversity [35]. Additionally, the supply of lignin - also based on aromatic subunits [36] - to the soil is far greater in an environment dominated by evergreen woody plants with tough long-lived leaves and lignified roots. Thus, we expected that genes dealing with these compounds would be relatively more abundant in the tropics. Fierer et al. [19] noted in their global survey that generally, these genes were less common in desert environments than non-desert environments, and Tripathi et al. [18] found the same trend.

7) Genes associated with secondary metabolism more common in the equatorial tropics. Going by the 'classical' view of stronger plant defenses in the tropics [7, 34], we hypothesized that because of the abundance of well-defended plant biomass in the tropics, compared to the sparse or non-existent layer of plant litter and root mass in polar regions, there should be greater exposure to secondary metabolites in general, in a tropical soil. This should select more strongly for genes to break down these metabolites in the tropics.

Additionally, in the more stable conditions of the tropics, interference competition between microbes in the soil should be more common and intense (as suggested by Schlesinger and 
Andrews [37]), and we expected that secondary metabolites produced by soil microbes would be more diverse and abundant - leading to greater relative abundance of genes for synthesizing or breaking down these substances. To some extent this category overlaps with 9) (see below), but category 9 only deals with 'known' antibiotics, whereas this may encompass a much broader range of compounds.

8) Greater abundance of genes associated with respiration in the equatorial tropics. Studies confirm that soil respiration rate is greater in warmer climates [38]. We hypothesized that in the much warmer equatorial tropics, where the conditions favor much more rapid growth of soil microbial communities [37], genes for respiratory processes should play a larger role as a proportion of the metagenome - for example with multiple copies of genes that synthesize enzymes associated with respiration.

9) Antibiotic resistance genes more common in the equatorial tropics. If interference competition among microbes is more important in the more stable environment of the equatorial tropics $[34,37]$, there should be a greater role of antibiotic production and greater selection for genes for antibiotic resistance. We hypothesized that known antibiotic resistance genes (as identified in the public server Metagenomic Rapid Annotations using Subsystems Technology 'MG-RAST') would be more common in the tropics than polar environments, due to their greater frequency of usage in competition by both fungi and bacteria. In accordance with this, Fierer et al. [19] found that these genes were less common in desert compared to non-desert environments. However by contrast Tripathi et al. [18] found that these genes did not differ in abundance along a precipitation gradient in Israel.

10) Greater abundance of genes associated with virulence/disease and defense in the tropics. One of the major groups of genes distinguished by MG-RAST, this category is based upon genes known to enhance pathogenicity in microbes infecting animal and plant hosts. However, 
this category is also known to be abundant in soil bacteria [39], most of which do not infect multicellular hosts. It is thought that these genes play an important part in inter-species interaction in soil, much of it in terms of defense against grazing or competition by protozoa or fungi [39]. On this basis, we hypothesized that the more stable environment of the equatorial tropics, with a lack of dormancy and the persistence of populations at relatively stable levels, would give more predictable co-occurrence of antagonistic species within the soil, leading to greater selection for carrying this category of genes in tropical compared to polar environments.

11) There will be greater connectedness in the equatorial tropics. A prevalent theme in descriptions of tropical biology is the intensity with which distinct species are linked by interactions in terms of mutualism, parasitism or predation $[11,12,34]$. This is explained in terms of the predictable co-occurrence and availability to participate in the interaction of distinct species, due to relatively constant climate and lack of a dormant season. The lack of a need to expend energy on physiological regulation in extreme conditions may also leave excess energy and resources which can allow these links to be maintained. Thus, network analysis is a tool providing an additional perspective on the soil ecosystem, including measures of the interactions between different taxa, and between particular taxa and particular gene functions [40-42]. In previous studies, network analyses have been used to identify the key connections between organisms under the different land use types [43, 44]. Continuing in this vein, we hypothesized that there would be evidence of greater linkage or connectedness in tropical metagenomes than polar ones. Connectedness in metagenomes measures the predictability of co-occurrence of sets of taxa in replicate samples. The more often taxa are found together, the higher the connectedness [44].

\section{Materials and Methods}




\subsection{Study sites}

This study was conducted in two regions, located at two extremes of latitude: tropical equatorial rainforest and high Arctic (Fig. S1, Table S1):

Tropical Sites: Borneo and Malay Peninsula. Tropical soil samples were collected within the lowland equatorial tropical rainforest biome at sites scattered across Malay Peninsula of west Malaysia (around $4^{\circ} 58^{\prime} \mathrm{N}, 117^{\circ} 48^{\prime} \mathrm{E}$ ) and Brunei Darussalam in Borneo (around $4^{\circ} 53^{\prime} \mathrm{N}$, $\left.114^{\circ} 72^{\prime} \mathrm{E}\right)$. The sampling sites all consist of primary tropical rainforest, dominated by large dipterocarp trees and have a complex and multi-layered forest structure [43].

The climate in Brunei has a mean annual rainfall exceeding $2300 \mathrm{~mm}$ and a tendency for two slightly drier periods in February/March and July/August, although even these 'dry' periods have rainfall in excess of evapotranspiration $[45,46]$. Mean annual temperature is $26.9^{\circ} \mathrm{C}$, and mean monthly temperature varies by less than $1^{\circ} \mathrm{C}$ during the year.

The three local sites in Malaysia are also reserves of primary old growth rainforest, on terra firma soils, a true tropical climate (with precipitation exceeding or equaling evaporation in all months), and peaks in rainfall in March and October. The mean annual temperature in all three sites is approximately $26.6^{\circ} \mathrm{C}$, with only around $0.1{ }^{\circ} \mathrm{C}$ variation in the monthly mean temperature during the year. The Meranti site is located at $2^{\circ} 41^{\prime} \mathrm{N}, 102^{\circ} 05^{\prime} \mathrm{E}$, and has an annual precipitation of around $2200 \mathrm{~mm}$. Ayer Hitam Forest Reserve is located at $2^{\circ} 59^{\prime} \mathrm{N}, 101^{\circ} 38^{\prime} \mathrm{E}$, with annual precipitation around $2270 \mathrm{~mm}$. The Port Dickson forest is located in the Tangjun Tuan reserve $\left(2^{\circ} 30^{\prime} \mathrm{N}, 101^{\circ} 52^{\prime} \mathrm{E}\right)$ at Port Dickson about $60 \mathrm{~km}$ from Kuala Lumpur. The Tangjun Tuan site has mean annual rainfall of $1980 \mathrm{~mm}$ (with precipitation exceeding or equaling evaporation in all months) and a mean annual temperature of $26.6^{\circ} \mathrm{C}$. The Tangjun 
Tuan forest is developed over a dolomitic limestone hill, although surface soils are acidic due to leaching of the clay derived from limestone weathering [17].

\section{Polar Sites: Svalbard, Zackenberg and Cambridge Bay.}

Svalbard: The high Arctic site in Svalbard, Norway $\left(78^{\circ} 55^{\prime} \mathrm{N}, 11^{\circ} 55^{\prime} \mathrm{E}\right)$, is located on a broad coastal plain area in north-western Svalbard. The temperature in July is cool (mean temperature $5^{\circ} \mathrm{C}$ ), and mean temperature during February is well below freezing $\left(-14^{\circ} \mathrm{C}\right)$. The growing season starts in late June and is over before the end of August. With mean annual temperature (MAT) below $-0^{\circ} \mathrm{C}$, much of Svalbard is underlain by permafrost. Mean annual precipitation is $300 \mathrm{~mm}$, mostly falling as snow outside the brief summer months [47]. High Arctic tundra in this area is covered mainly by a mix of polar desert, with almost no vegetation, and sparse dry high Arctic tundra with incomplete ground cover, interspersed with bare ground, stones and raised stony frost polygons. We sampled separate local sites three main tundra types scattered across several kilometers of the coastal plain, selected based on percentage vegetation cover. Although differing in overall percentage vegetation cover, all had a broadly similar mosaic of vegetated areas dominated by cushion plants, cyanobacteria or mosses, interspersed with bare areas. The three tundra types are: 1) 'high vegetation coverage tundra' (HV) having around 90$100 \%$ vegetation cover on average, and located several meters above sea level near the coastline, 2) 'intermediate vegetation coverage tundra' (IV), with a vegetation coverage between $30 \%$ and $75 \%$, and located on slightly raised terraces, and 3) 'low vegetation coverage tundra' (LV) having a vegetation cover less than $50 \%$ in average, showing more bare patches and located on well-drained gravelly raised banks and terraces more than several hundred meters inland $[17,47]$.

Zackenberg Valley $\left(74^{\circ} 30^{\prime} \mathrm{N}, 20^{\circ} 30^{\prime} \mathrm{W}\right)$. This site a wide lowland valley located in the southern part of the National Park of North and East Greenland. It is situated in a transition zone between 
the relatively lush and snow-rich southern part of the high Arctic and the more barren and arid northern part [48]. It is dominated by Quaternary non-calcareous sediments with significant periglacial activity and continuous permafrost, with a mean annual temperature of $-9.1{ }^{\circ} \mathrm{C}$ (measured between 1997 and 2005). The maximum monthly mean temperature is $5.8^{\circ} \mathrm{C}$ in July, and the minimum monthly mean is $-20.2^{\circ} \mathrm{C}$ in January [49]. The mean annual precipitation is about $223 \mathrm{~mm}[50]$.

Cambridge Bay $\left(69^{\circ} 6^{\prime} \mathrm{N}, 105^{\circ} 8^{\prime} \mathrm{W}\right)$ is located on Victoria Island in Nunavut, Canada. The climate at Cambridge Bay is largely influenced by the geographic position of Victoria Island and the hydro-climate patterns of the Arctic Ocean. Monthly average temperatures above $0^{\circ} \mathrm{C}$ occur in June through August, when rainfall is the highest, peaking at more than $30 \mathrm{~mm}$. The monthly temperature varies from $-33.50^{\circ} \mathrm{C}$ in February to $8.35^{\circ} \mathrm{C}$ in July between 1950 and 2010 , with an annual average of $-14.58^{\circ} \mathrm{C}[51]$.

\subsection{Soil sampling and DNA extraction}

Tropical sites. Tropical soils were taken from the different localities described above, in Malaysia and Brunei (Table S2). For each individual sample, a randomly located $10 \mathrm{~m}$ x $10 \mathrm{~m}$ square was marked out within the forest. The top $5 \mathrm{~cm}$ of soil was collected as a $10 \mathrm{~cm}$ diameter cylinder from the four corners and center of each quadrat. After gently removing the surface moss, leaves and stones, soil was placed in a sterile plastic bag. The combined soil, amounting to c. $500 \mathrm{~g}$, was then gently mixed. Samples from the same site/local site were taken at least $100 \mathrm{~m}$ apart from one another. We report here on nine samples from Malaysia and six samples from Brunei - reduced from an original ten samples in each due to failure of the metagenome sequencing in some samples. 
High Arctic site sampling. Twelve samples are included here from Svalbard, three from Cambridge Bay in Canada and two from Zackenberg in Greenland (Table S2). Soil samples were collected in exactly the same way as with the tropical sites. At Zackenberg three samples were originally taken, but one failed in sequencing.

In each case (both tropical and Arctic samples), the collected soil samples were homogenized by sieving using a $2 \mathrm{~mm}$ sieve and stored at $-20^{\circ} \mathrm{C}$ until DNA extraction [43]. Then, at the laboratory, we carried out four extractions from each sample consisting of 0.25-0.3 g air dried weight of soil to ensure sufficient DNA in every case, using MoBio Power Soil DNA extraction kit (MoBio Laboratories, Carlsbad, CA), following the manufacturer's instructions.

\subsection{Soil chemical analyses}

Soil chemical parameters including $\mathrm{pH}$, total carbon, total nitrogen and available phosphorous were measured for each sample at the National Instrumentation Center for Environmental Management (NICEM, South Korea) based on the standard protocol of the Soil Science Society of America (SSSA). We conducted the chemical analysis for all samples except for the samples collected from Greenland and Canada. The chemical data for those samples are not currently available due to the necessary analyses not yet having been carried out by the research teams who provided the DNA samples.

\subsection{Shotgun metagenomic sequencing and data processing}

DNA samples were sequenced for whole metagenome at Celemics (Celemics, Inc., Seoul, Korea) using Illumina HiSeq2000 platform $(2 \times 150$ bp) (Illumina, Inc.). DNA library for metagenome analyses was prepared following the Illumina HiSeq DNA library preparation protocol. 
The Metagenomics Rapid Annotation (MG-RAST) pipeline was used to annotate the unassembled DNA sequences [52]. The taxonomic and functional profiles were assessed using RefSeq and Subsystems databases. Sequences having $\geq 5 \%$ bp with $\leq 10$ phred scores were filtered out before bioinformatics analyses. Raw unassembled reads were annotated in MGRAST using Hierarchical Classification subsystems with a maximum e-value cutoff of $10^{-5}$, a minimum percent identity cutoff of $60 \%$ and a minimum alignment length cutoff of 15 . These profiles were then normalized for differences in sequencing coverage by calculating percent distribution, prior to downstream statistical analysis.

\subsection{Statistical analyses}

We used a t-test for normal data and Wilcoxon-rank sum test for non-normal data in R software package 2.15.2 to test whether the relative abundances of taxonomical groups or functional gene categories were significantly different between samples in different equatorial tropical and polar sites.

To assess whether soil microbial community composition clustered according to different sites, we performed a non-metric multidimensional scaling (NMDS) plot of taxonomy (ReSeq taxonomic profile at class level) and function (Subsystems at function level 3) using the 'metaMDS' function in the Vegan package of R [53]. Then, we used the 'envfit' function in package Vegan in $\mathrm{R}$ version 3.0.1. to test if community composition was structured in relation to any of the environmental variables measured.

We calculated Shannon index from matrices of taxonomic and functional richness, respectively to estimate the taxonomic and functional alpha-diversity. The deepest assignments of RefSeq taxonomy (species Level) and Subsystems function (at MG-RAST Level 3) were used to calculate the alpha-diversity, as the concept of diversity is based on species level. 
To understand the relationships between the soil microbial community taxonomy and functions, we performed network analysis. To make a clear interpretation of the microbial connectivity and decrease the complexity of the networks, we chose higher taxonomic level (class level) and higher level functional classification (level 1). As only two of our sample sets - Brunei and Svalbard - could provide five replicates per local site (as required for the connectedness analysis) we only compared these two sets for connectedness. Furthermore, the computation of correlation at higher levels of classification avoids ecological signals and artifacts that may occur due to inaccurate assignment on lower levels [41]. All possible Spearman's rank correlation coefficients were calculated and only correlations with $r>0.9$ and $P<0.01$ were selected to reduce the network complexity. The network topology was described based on set of measures, average clustering coefficients, average path length and modularity. The interactive platform Gephi was used to explore and visualize the structure of network. We generated 1000 random networks of equal size (same number of nodes and edges) as each of the original networks and compared their topological properties with the observed network to determine that the generated networks are not random. This analysis was performed using the 'erdos.renyi.game' function of the 'igraph' R package.

The shotgun metagenomic sequence data used in this study are deposited in the MG-RAST server under project ID 17194 (http://metagenomics.anl.gov/linkin.cgi?project=17194), project ID 10310 (http://metagenomics.anl.gov/linkin.cgi?project=10310), project ID 10865 (http://metagenomics.anl.gov/linkin.cgi?project=10865) and project ID 18555 (http://metagenomics.anl.gov/linkin.cgi?project=18555).

\section{Results}

3.1. Taxonomy and dominant microbial taxa 
After quality control, a total of 97 million sequences remained from 32 samples (Table S2).

Out of these, a total of $34-50 \%$ of the sequences were annotated as protein using $\mathrm{E}<1 \times 10^{-5}$, and 15-bp minimum alignment length on MG-RAST server.

In both the equatorial tropical rainforest and high Arctic tundra, most of the shotgun metagenomic reads belonged to bacteria, comprising on average $97.5 \%$ of the total hits to the RefSeq database followed by eukaryotes (1.5\%), archaea (1\%) and less than $0.1 \%$ for viruses. The relative abundance of these detected groups was significantly different between the two biomes, with equatorial rainforests having slightly higher abundance of bacteria $(\mathrm{w}=29, P<$ $0.001)$ and lower abundance of archaea $(\mathrm{w}=238, P<0.001)$ compared to the polar sites. Proteobacteria was the most dominant bacterial phylum among the metagenomic sequence data with an average percentage of 47\%, followed by Actinobacteria (24\%), Acidobacteria (5\%), Firmicutes (5.5\%), and then Bacteroidetes, Cyanobacteria, Chloroflexi and Planctomycetes each with less than 3\% (Fig. 1). The relative abundance of these most abundant bacterial phyla differed significantly between equatorial tropical sites and high Arctic sites (All $P<0.05$ ), with tropical samples having greater relative abundance of Proteobacteria and Acidobacteria compared to polar soil samples (Table 1). At the family level, the most dominant bacterial families were significantly more abundant in tropical soils compared to high Arctic soils (Table S3). The most common archaeal families did not differ between polar and tropical sites except for except for Halobacteriacea that was significantly greater in high Arctic soils ( $\mathrm{w}=239, P<$ 0.001), whereas, the families Sulfolobaceae, Methanobacteriacea, Methanocaldococcoceae and Thermoplasmataceae were significantly greater in tropical sites than high Arctic sites (Table S3). The relative abundance of different fungal phyla did not differ between the two biomes $(P$ $>0.05)$. Similarly, the most dominant families belonging to eukaryotes and viruses did not 
show any difference between the two latitudes, except for few families representing a very low percentage relative abundance (Table S3).

\subsection{Dominant functional genes}

Using the Subsystems data base [54], we analyzed the functional profile of the shotgun metagenomic sequences to test our hypotheses/predictions on the latitudinal difference in soil microbial community and functions between the equatorial tropics and high Arctic tundra. Subsystems data base is a set of functional roles or a group of genes acting together in a biological process (e.g. in a metabolic pathway). These functions are grouped into four subsystem categories (Subsystem level 1- highest level, Subsystem level 2- intermediate level, Subsystem level 3- similar to a KEGG pathway, and Subsystem level 4- actual functional assignment to the feature in question KEGG Orthologs). The Subsystems technology connects these functional roles to specific genes in specific genomes. It includes assertions of functions for over 500,000 protein-encoding genes in over 500 bacterial and archaeal genomes relating to over 6,200 functional roles [55]. 28 functional gene categories (Subsystems level 1) were found in our samples. Most of the detected functional gene categories differed significantly in abundance between equatorial and polar soils, except for genes related to fatty acids, cofactors, vitamins, prosthetic groups and pigments, genes related to cell division and cell cycling, and genes related to phosphorous, sulfur and secondary metabolisms, genes related to nucleosides and stress response genes (Table 2). Gene categories that were significantly more abundant in polar sites than in the equatorial samples were related to dormancy, DNA metabolism, phages, prophages, plasmids and transposable elements, regulation and cell signaling, etc. Although CRISPR genes were at low abundance in our samples (representing around $0.01 \%$ of total sequences), their abundance was significantly different between the two biomes ( $\mathrm{w}=237, P<$ 0.001), with polar soils having significantly greater abundance than tropical sites (Fig. S2). 
However, functional genes related to metabolism of aromatic compounds and respiration were significantly more abundant in the tropics than the polar soils (Fig. 2).

\subsection{Microbial community composition}

The overall soil microbial community composition, based on Bray-Curtis similarity revealed a significant difference between the polar and tropical sites. Soils from each site harbored communities that clustered apart from each other when community differences were measured based on either taxonomy (RefSeq taxonomic profile at class level: ANOSIM Global $R=0.57$, $P=0.001$ ) or function (Subsystems function level 3 of functional profile: ANOSIM Global $R$ $=0.44, P=0.001)$ of shotgun metagenomic sequences, with both metrics having approximately similar patterns (Fig. 3). The 'envfit' function in R showed that the measured soil parameters including soil $\mathrm{pH}$, carbon content and nitrogen content significantly explained a proportion of the community composition for both taxonomy and functions and were a structural factor in soil microbial community composition (Fig. S3).

The measured soil parameters were significantly different among different polar and tropical sites except for soil total carbon $(\mathrm{w}=70.5, P=0.50)$, with higher $\mathrm{pH}(\mathrm{w}=168, P<0.001)$ was found in Svalbard high Arctic tundra soils. However, total nitrogen $(\mathrm{w}=35, P=0.012)$ and available phosphorous $(\mathrm{w}=37, P=0.014)$ were significantly lower in the analysed Svalbard high Arctic soils compared to tropical soils (Fig. S4).

\subsection{Microbial community diversity}

Our results showed that the alpha-diversity of taxonomic groups and total functional diversity using Shannon diversity differed between high Arctic tundra and tropical samples. Contrary to our hypothesis, Arctic tundra had significantly higher taxonomic diversity (at species level) and functional diversity (at function level) than tropical soils with $\mathrm{w}=96, P<0.001$ (Fig. 4). 
Shannon index revealed the same trend for both taxonomic and functional diversities of bacteria $(\mathrm{w}=96, P<0.001)$ and eukaryotes $(\mathrm{w}=88, P=0.001)$, with higher species diversity was observed in high Arctic tundra. However, archaea, viruses and fungi did not show any significant difference in diversity between the two latitudes (Fig. S5).

\subsection{Relationship between microbial taxonomy and function}

We conducted a correlation-based network analysis to study the relationship between the taxonomy and functions of the shotgun metagenomic sequences between only two locations that individually had sufficient numbers of replicate samples: the high Arctic tundra of Svalbard, and tropical rainforest of Brunei.

In the connectivity analysis, based on strong significant positive correlations $(r>0.90$ and $P<$ 0.05), Brunei rainforest samples had slightly higher positive correlations than Svalbard high Arctic tundra, with respectively 35 nodes and 137 edges in tropical rainforest and 50 nodes and 104 edges in Arctic tundra (Table 3, Fig. 5). The microbial taxa presenting the highest number of positive correlations with other taxonomic and functional groups belonged to Thermotogae in tropical rainforest and Cytophagia in high Arctic tundra, and they were among the less abundant taxa in our samples (Table 3).

\section{Discussion}

Overall comparison of taxonomic and functional structure. The tropical and Arctic sites fell into two distinct clusters on the NMDS, which suggests that overall there is a consistent 'high Arctic' metagenome that is distinct from a 'tropical rainforest' metagenome. This is true for both the taxonomic (Fig. 4a) and functional (Fig. 4b) composition. When abundances of 
particular gene categories are compared by site as well as region, it is also clear that these patterns are consistent (Fig. S6).

At the very broadest level of taxonomic composition, the equatorial tropical and high Arctic metagenomes were similar. Bacterial DNA sequences were overwhelmingly the most abundant in the metagenomes (about $98 \%$ of identifiable reads), followed by eukaryote, archaeal and virus sequences. Relative abundances of each major kingdom were similar in both biomes, despite the major differences in climate and overall ecosystem structure.

It is clear from their MG-RAST classifications that in both the equatorial tropics and High Arctic, most of the genes discussed here are of bacterial origin. The proportion of detected fungal genome material is very low, which is actually standard in studies of the upper mineral soil $[18,56]$. The low abundance of fungi in metagenomes is surprising to most who study soil biology, and the importance of fungi in soil processes seems to outstrip their low abundance. In environmental DNA studies, fungi are generally much more abundant in the leaf litter layer than in soil [57]. It is interesting that despite the large differences in climate, vegetation coverage types and various aspects of the soils, the relative abundance of bacteria, eukaryotes, archaea, etc. (as deduced from DNA reads) is nearly constant between the tropical and high arctic zones we studied here. This implies a basic similarity in functional structure of these two sets of soils, despite their very different environments, and begs the question of whether all or nearly all the world's soils might have the same relative abundances of these various kingdoms of life.

Functional analysis of the metagenomes using the MG-RAST database reveals many differences between the relative abundances of genes in the equatorial tropical and polar samples. Certain hypotheses turn out to be as predicted based on general theory of how tropical and high latitude ecosystems and community processes may be expected to differ. In other 
cases, there is either no difference, or the difference is opposite to what was predicted (See Table 4):

In terms of representation of bacterial groups, the Arctic samples differed from the tropical sites mainly in greater abundances of Firmicutes, Bacteroidetes, Cyanobacteria and especially Deinococci. Amongst the factors causing the very different community in the Arctic, the lack of a covering canopy of plants would explain the importance of Cyanobacteria, which are important primary producers in the high Arctic tundra. The much greater abundance of Deinococci may be explained in terms of the continuous exposure to solar radiation under cloudless skies in the summer months, and the frequent freeze-drying of the surface - both factors that tend to select for Deinococci $[58,59]$. The high Arctic samples, despite their scatter on the ordination, were distinct from tropical samples (Fig. 3), suggesting that the difference in the environment is so extreme that a relatively distinct taxonomic composition results.

With respect to the various hypotheses regarding the differences in functional metagenome structure, there is a decidedly mixed picture relative to what was expected:

1) Greater diversity of taxa and gene functions in the tropics. We expected to find higher alpha diversity of both taxa and gene functions in tropical equatorial forest than in high Arctic tundra. In fact, we found greater microbial diversity - based on both taxa and gene functions - in high Arctic sites compared to tropical sites.

We hypothesized that there would be a latitudinal difference in taxonomic alpha diversity between high Arctic and tropical environments, with microbial diversity being lower in the high Arctic. There was, surprisingly, a higher diversity in the high Arctic samples compared to the tropical ones. Our study of soil nematodes on some of the same locations found no difference in alpha-diversity of nematodes between Svalbard and the tropics [17]. In another study that took a biogeographic approach, with amplicon samples scattered across the Americas 
(though with very few samples from either equatorial or polar environments), Fierer and Jackson [60] found that soil bacterial community showed no latitudinal diversity trend. It appears that unlike the striking diversity differences for macroorganisms - with much higher tropical diversity seen for plants and insects, for example - microbes do not show the classic latitudinal trend. The Shannon diversity difference is quite large, around 1.3 units, comparable with but opposite to the Shannon diversity index difference for tropical vs temperate trees, which is usually $1-2$ units [61-65].

There were also striking Arctic-tropical differences in broad taxonomic composition, with the total soil communities clustering separately on an NMDS (Fig. S3). This might be due to factors directly related to climate or soil parameters such as organic matter content, total nitrogen content or $\mathrm{pH}$. For instance, soils from the Svalbard sites contained lower abundances of Acidobacteria, as expected due to their higher pH compared to tropical soils (Fig. 2 and Fig. S4), since Acidobacteria are strongly associated with low pH soils [66, 67] (the other two Arctic sites have no available $\mathrm{pH}$ data, but also contain similarly low abundances of Acidobacteria).

Our results challenge a longstanding theory in ecology that biodiversity generally decreases towards polar regions $[68,69]$, and contrast a conclusion from the Fierer et al. [19] study, that microbial diversity in polar desert is lower than in other biomes. These findings are consistent with the study of Neufeld and Mohn [70], who reported unexpectedly higher bacterial diversity in high Arctic tundra compared to boreal forest soils. The relationship between bacterial diversity and $\mathrm{pH}$ is well established [71], and it may be that soil chemical parameters rather than direct climate effects overwhelm any other patterns on a global scale, even when polar and equatorial regions are being compared. Another reason for greater microbial diversity in the high Arctic may be due to the soil organisms having lower metabolic activity and thus less 
active competition, with less ecological filtering of functional traits. Arctic soils tend to have relatively slow recycling of nutrients as well as lower mean temperature, leading to longer annual periods of low metabolic activity of microorganisms [72, 73].

2) Genes for dormancy/sporulation more common in the high Arctic. Here the result conforms to our expectations based on 'classical' ecological theory: dormancy genes were more common in the Arctic samples than in the tropical samples. It may be that the instability in temperatures in the high Arctic requires frequent dormancy to escape the environmental conditions inimical to growth and survival. A major selection factor for dormancy genes in soil organisms may be periods of local nutrient depletion, perhaps on the microscopic spatial scale of an individual grain of soil [74], and that this may overwhelm any effects relating to differences in climate.

3) Stress response genes more common in the high Arctic. Contrary to our expectations, stress response genes were no more common in the high Arctic sites than in the equatorial tropics. It appears that a priori expectations about how much 'stress' soil biota is exposed to may not be accurate. At least if there is more stress in the high Arctic, the genes that are needed are not those identified by MG-RAST. It is possible that even in the tropical environment, very small scale 'stressful' environments - for example from osmotic stress related to release of nutrients or very short term and localized changes in water content - dominate bacterial ecology much more than broad climate $[75,76]$. Again, this calls into question the view that polar environments are more 'stressful' over the lifetime and on spatial scale of microbial cells, compared to tropical environments.

4) Genes associated with replication and cell division more common in the equatorial tropics. In contrast to our predictions, relative abundance of genes associated with cell division did not differ between the high Arctic and tropical sites. Our results parallel those of Fierer et al. [19], who (in a more limited set of samples) found higher abundance of genes associated with cell 
division and cell cycle in polar desert soils than non-desert soils. This difference may be related to the extreme environmental conditions in the high Arctic, leading to higher abundance of the products of these core genes to facilitate the genomic stability in microbial communities. It is important, however, to bear in mind that differences in abundance of 'core' genes such as these - dealing with functions likely to be present in all cells - might have more to do with changes in abundance of other types of genes. Since the genes in metagenomes here are compared in terms of relative rather than absolute abundances, decreased abundance of one gene category (e.g. secondary compound metabolism) would automatically tend to produce an increased relative abundance of other categories, such as these core genes for cell replication and division - even though the increase in core genes might have no direct basis in terms of functional selection.

5) Genes associated with viruses and anti-virus defenses more common in the equatorial tropics. In contrast to our hypothesis, the results showed significantly greater relative abundance of virus and virus-like elements in the polar soils compared to the tropical sites. Likewise, CRISPR elements (an anti-viral defense) were significantly more abundant in the polar soils. It appears that the assumption of greater disease pressure in the tropics may be incorrect. However, it is difficult to gauge whether the levels of virus abundance seen in our samples reflect long term means, or temporary fluctuations in viral populations. It is possible that viruses could show large abundance fluctuations during the growing season, analogous to the herbivorous insect or mammalian herbivore outbreaks that can occur in temperate and boreal forests [77].

6) Genes associated with metabolism of aromatic compounds more common in the equatorial tropics. As predicted, these genes are relatively more common in the tropical sites, which may 
reflect the much higher levels of vascular plant biomass - the main source of carbon in most soils and especially tropical soils [78] - together with the lignin and aromatic secondary compounds that they bring to the soil.

7) Genes associated with secondary metabolism more abundant in the equatorial tropics. Contrary to our prediction, genes associated with secondary metabolism did not vary in relative abundance between polar and tropical sites. While it is plausible that the quantity and diversity of secondary compounds in a tropical forest would greatly exceed those in a sparsely vegetated polar ecosystem with few plant species, recent studies found apparently analogous results suggesting that there is no overall difference in secondary compound categories and abundance in leaves between boreal, temperate and tropical environments $[6,79]$. There have been no studies which compared the output and diversity of secondary compounds produced by soil microbes from polar and equatorial regions.

8) There will be greater abundance of genes associated with respiration in the tropics. These results conform to our expectations, with respiration-related genes more common in the tropical sites. Previous studies showed that soil respiration and microbial growth rate are greater in warmer climates $[38,80,81]$. However although this could simply be achieved by the same enzymes working faster in warmer temperatures, it is possible that respiration-related genes are present in greater copy numbers in warmer conditions to enable cells to take advantage of the conditions.

Although there have been no previous studies which explicitly compared the functionality of soils at the high Arctic and equatorial tropical extremes, certain general comparisons are possible. Previous studies $[38,80]$ have shown that soil respiration and microbial growth rates are higher in the equatorial tropics compared to colder climates. The stable environmental conditions of the tropics - constant warm temperature and available soil moisture content - 
favour greater plant growth which is the main source of carbon in tropical soils [35]. The higher metabolic rate in the tropics combines with greater rates of supply of plant litter to give much more rapid overall decomposition rates in the tropics than the high Arctic. In Arctic ecosystems, slow litter decomposition and soil organic matter turnover result in low rates of nutrient supply to plant roots, decreasing nutrient cycling and further decreasing plant growth in cold climates [82].

9) Antibiotic resistance genes more common in the tropics. We hypothesized that antibiotic production by soil biota would be more common - and ecologically more important - in tropical soils, and there would be correspondingly greater selection pressure for resistance to antibiotics, conferred by genes that alter the target site or help to eliminate the antibiotic from cells. Contrary to our expectations, in our samples, antibiotic resistance genes appear to be no more common in the polar arctic sites than in the equatorial tropics. It appears that the types of interference competition that involve antibiotics are as important in polar environments as in the tropics.

10) There will be greater abundance of genes associated with virulence/disease and defense in the tropics. Contrary to our hypothesis, the high Arctic sites had a greater abundance of these genes involved in cell-cell interactions than the tropical sites. This contrasts with the conclusions of Møller [83], who suggests that the defensive interactions that these genes are used for in soil are stronger/more frequent in the equatorial tropics than in polar regions. It is possible, perhaps, that the cell-cell interactions that these genes govern are involved in more abundant and intricate mutualisms in high Arctic soils - made necessary by the physiological challenges of the high Arctic environment.

11) Greater connectedness in the tropics. We predicted that the soil biota of tropical rainforest would have greater number of correlations and greater network complexity due to the stable 
climate and lack of environmental stress in the equatorial tropics [35], resulting in more specialized biotic interactions [42]. As mentioned in Methodology, due to differences in sample numbers per site, we used only one tropical site and one Arctic site: Brunei as representative of the tropics and Svalbard for the high Arctic. We did not include the other sampling sites in this analysis as they had fewer than five samples each. Our results indicated that the Brunei tropical rainforest soils do have higher network complexity than Svalbard high Arctic soils (Fig. 5). Thus, our hypothesis is supported. However, while the difference is statistically significant, it is not very large (Table 3).

Connectedness in the soil biota has been shown to increase during succession $[84,85]$, suggesting that in some ways our Arctic system is more like an early successional state in terms of the intricacy and tightness of its connections - even though both the Arctic and tropical systems we compared were clearly mature, late successional systems, at least on the overall site scale. It is intriguing that these differences may exist spatially, as well as temporally, and this deserves further investigation. In the case of the Arctic, it is possible that more generalized behavior in terms of mutualists or antagonists is driven by the far more variable climatic conditions. The relatively slow supply of primary and secondary production relative to the rate of micro-disturbances such as frost heave might also be regarded as keeping the system in a state that resembles a permanent secondary succession.

It is important to note that there are differences in average soil parameters between our Arctic and tropical samples. For example, $\mathrm{pH}$ is higher and organic matter content is much lower in the Arctic samples. It is possible that the contrast in soil chemistry, rather than climate, produces the patterns seen here and if we were to compare samples with soil chemistry that was similar, these patterns might be very different. However, soil chemistry itself is a product of climate and our samples are broadly representative of high Arctic and equatorial tropical 
soils in terms of $\mathrm{pH}$ [86-88]. Thus, it is difficult and perhaps meaningless to disentangle the direct role of climate, and the indirect role of climate acting through soil chemistry.

\section{Conclusions}

From the 'classical' viewpoint of the equatorial tropics as represented in our hypotheses, with much more intense biotic interaction compared to the poles, the picture we have found here in the metagenomes is decidedly mixed. In terms of this classical paradigm, around half of our hypotheses for how the soil metagenomes of equatorial tropical and polar environments should differ, actually turned out to be supported (Table 4). However, in many instances the expected difference between tropical and polar soil biota was not found, and in other instances the polarto-tropical difference was the opposite of what we had predicted (Table 4). This adds an intriguing new perspective on how ecological and evolutionary processes vary around the world. It appears, for example, that the intensity of biotic interaction by various measures (e.g. cell-cell interaction genes, antibiotic resistance genes, viruses and anti-virus defenses) is no greater in the tropics than the high Arctic. The degree of connectedness, while slightly greater in the tropics, is not strikingly different. It appears that, considering all these aspects together, the polar soil ecosystem is roughly as complex, intricate and as interconnected as the tropical one. The implications for ecosystem resilience should be considered. Does this mean, for example, that tropical soil ecosystems are likely to be any different in terms of resilience from arctic ones? If they indeed they do differ in resilience, by what other mechanisms can we explain this?

In the broadest context, our findings add more material towards an ongoing reassessment of the differences between tropical and higher latitude community and ecosystem processes [34]. 
The ecological patterns predicted for larger organisms (e.g. herbivory, plant defenses, coloration) are in some doubt, and we find here the soil microbial world shows only a rather mixed degree of agreement with the classical expectations, depending on which aspects of the soil metagenomes one focuses on.

It is necessary to bear in mind that, as there have been almost no previous attempts to translate the theory of tropical biology and latitudinal differences to the world of soil metagenomes (Fierer et al. [89] being the only possible exception, although they focused less on effects of latitude and more on other inter-biome differences) we were forced to make ad hoc judgments as to what patterns of gene function would be expected. It is possible that with further discussion and thought, the hypotheses might be different. We also limited ourselves here to comparing the extremes, the 'end points' of the latitudinal gradient, in the hope that they might reveal most clearly whatever patterns exist.

Our findings here may help to bring insights into the workings and unifying principles of community and ecosystem ecology, with both intellectual and practical benefits. There is also a need to critically examine in detail the chemical processes occurring within the soil community (including experimental approaches to study these) [90-92] that may underlie the patterns we find here, and to further consider their implications.

\section{Acknowledgments}

This work was partly supported by a grant from the Polar Academic Program (PAP) funded by Korea Polar Research Institute (KOPRI) under the number 0409-20140091. This work was also partly supported by a grant from the National Research Foundation (NRF) funded by the Korean government, Ministry of Education, Science and Technology (MEST) under the number NRF-0409-20150076. 


\section{References}

1. Gaston K, Blackburn T (2008) Pattern and process in macroecology. John Wiley \& Sons

2. Gaston KJ (2000) Global patterns in biodiversity. Nature 405: 220-227.

3. Lyons SK, Willig MR (2002) Species richness, latitude, and scale-sensitivity. Ecology 83: 47-58.

4. Pennings SC, Silliman BR (2005) Linking biogeography and community ecology: latitudinal variation in plant-herbivore interaction strength. Ecology 86: 2310-2319.

5. Pimm SL, Brown JH (2004) Domains of diversity. Science 304: 831-833.

6. Moles AT, Ollerton J (2016) Is the notion that species interactions are stronger and more specialized in the tropics a zombie idea? Biotropica 48: 141-145.

7. Coley PD, Barone J (1996) Herbivory and plant defenses in tropical forests. Annual review of ecology and systematics 27: 305-335.

8. Becerra JX (2015) On the factors that promote the diversity of herbivorous insects and plants in tropical forests. Proceedings of the National Academy of Sciences 112: 60986103.

9. Freestone AL, Osman RW, Ruiz GM, Torchin ME (2011) Stronger predation in the tropics shapes species richness patterns in marine communities. Ecology 92: 983-993.

10. Garibaldi LA, Kitzberger T, Ruggiero A (2011) Latitudinal decrease in folivory within Nothofagus pumilio forests: dual effect of climate on insect density and leaf traits? Global Ecology and Biogeography 20: 609-619.

11. Janzen DH (1970) Herbivores and the number of tree species in tropical forests. The American Naturalist 104: 501-528.

12. MacArthur RH (1969) Patterns of communities in the tropics. Biological Journal of the Linnean Society 1: 19-30.

13. Anderson MG, Gill BJ, Briskie JV, Brunton DH, Hauber ME (2013) Latitudinal differences in the breeding phenology of Grey Warblers covary with the relationship to the prevalence of parasitism by Shining Bronze-Cuckoos. Emu 113: 187-191. doi: https://doi.org/10.1071/MU12086

14. García D, Zamora R, Gómez JM, Jordano P, Hódar JA (2000) Geographical variation in seed production, predation and abortion in Juniperus communis throughout its range in Europe. Journal of Ecology 88: 435-446. doi: 10.1046/j.1365-2745.2000.00459.x

15. Prosser JI, Nicol GW (2008) Relative contributions of archaea and bacteria to aerobic ammonia oxidation in the environment. Environmental microbiology 10: 2931-2941. 
16. Bardgett RD, Freeman C, Ostle NJ (2008) Microbial contributions to climate change through carbon cycle feedbacks. The Isme Journal 2: 805. doi: 10.1038/ismej.2008.58

17. Kerfahi D, Tripathi BM, Porazinska DL, Park J, Go R, Adams JM (2016) Do tropical rain forest soils have greater nematode diversity than High Arctic tundra? A metagenetic comparison of Malaysia and Svalbard. Global Ecology and Biogeography 25: 716-728.

18. Tripathi BM, Moroenyane I, Sherman C, Lee YK, Adams JM, Steinberger Y (2017) Trends in taxonomic and functional composition of soil microbiome along a precipitation gradient in Israel. Microbial ecology: 1-9.

19. Fierer N, Leff JW, Adams BJ, Nielsen UN, Bates ST, Lauber CL, Owens S, Gilbert JA, Wall DH, Caporaso JG (2012) Cross-biome metagenomic analyses of soil microbial communities and their functional attributes. Proceedings of the National Academy of Sciences 109: 21390-21395.

20. Tedersoo L, Bahram M, Põlme S, Kõljalg U, Yorou NS, Wijesundera R, Ruiz LV, VascoPalacios AM, Thu PQ, Suija A (2014) Global diversity and geography of soil fungi. science 346: 1256688.

21. Cox F, Newsham KK, Bol R, Dungait JAJ, Robinson CH (2016) Not poles apart: Antarctic soil fungal communities show similarities to those of the distant Arctic. Ecology Letters 19: 528-536. doi: 10.1111/ele.12587

22. Chu H, Fierer N, Lauber CL, Caporaso JG, Knight R, Grogan P (2010) Soil bacterial diversity in the Arctic is not fundamentally different from that found in other biomes. Environmental Microbiology 12: 2998-3006. doi: 10.1111/j.1462-2920.2010.02277.x

23. Dong K, Tripathi B, Moroenyane I, Kim W, Li N, Chu H, Adams J (2016) Soil fungal community development in a high Arctic glacier foreland follows a directional replacement model, with a mid-successional diversity maximum. Scientific Reports 6: 26360. doi: $10.1038 /$ srep26360

https://www.nature.com/articles/srep26360\#supplementary-information

24. Colwell RK, Hurtt GC (1994) Nonbiological gradients in species richness and a spurious Rapoport effect. The American Naturalist 144: 570-595.

25. Hawkins BA, Field R, Cornell HV, Currie DJ, Guégan J-F, Kaufman DM, Kerr JT, Mittelbach GG, Oberdorff T, O'Brien EM (2003) Energy, water, and broad-scale geographic patterns of species richness. Ecology 84: 3105-3117. 
26. Hillebrand H (2004) On the generality of the latitudinal diversity gradient. The American Naturalist 163: 192-211.

27. Jablonski D, Roy K, Valentine JW (2006) Out of the tropics: evolutionary dynamics of the latitudinal diversity gradient. Science 314: 102-106.

28. Weiser MD, Enquist BJ, Boyle B, Killeen TJ, Jørgensen PM, Fonseca G, Jennings MD, Kerkhoff AJ, Lacher Jr TE, Monteagudo A (2007) Latitudinal patterns of range size and species richness of New World woody plants. Global Ecology and Biogeography 16: 679-688.

29. Fuhrman JA, Steele JA, Hewson I, Schwalbach MS, Brown MV, Green JL, Brown JH (2008) A latitudinal diversity gradient in planktonic marine bacteria. Proceedings of the National Academy of Sciences 105: 7774-7778.

30. Lubzens E, Cerda J, Clark M (2010) Dormancy and resistance in harsh environments. Springer Science \& Business Media

31. Varin T, Lovejoy C, Jungblut AD, Vincent WF, Corbeil J (2012) Metagenomic analysis of stress genes in microbial mat communities from Antarctica and the High Arctic. Applied and environmental microbiology 78: 549-559.

32. Raich JW, Clark DA, Schwendenmann L, Wood TE (2014) Aboveground tree growth varies with belowground carbon allocation in a tropical rainforest environment. PloS one 9: e100275.

33. Horvath P, Barrangou R (2010) CRISPR/Cas, the immune system of bacteria and archaea. Science 327: 167-170.

34. Moles A (2013) Dogmatic is problematic: Interpreting evidence for latitudinal gradients in herbivory and defense. Ideas in Ecology and Evolution 6.

35. Kotowska MM, Leuschner C, Triadiati T, Meriem S, Hertel D (2015) Quantifying above-and belowground biomass carbon loss with forest conversion in tropical lowlands of Sumatra (Indonesia). Global change biology 21: 3620-3634.

36. Boerjan W, Ralph J, Baucher M (2003) Lignin biosynthesis. Annual review of plant biology 54: 519-546.

37. Schlesinger WH, Andrews JA (2000) Soil respiration and the global carbon cycle. Biogeochemistry 48: 7-20.

38. Raich JW, Schlesinger WH (1992) The global carbon dioxide flux in soil respiration and its relationship to vegetation and climate. Tellus B 44: 81-99. 
39. Søborg DA, Hendriksen NB, Kroer N (2014) Occurrence and expression of bacterial human virulence gene homologues in natural soil bacteria. FEMS microbiology ecology 90: 520-532.

40. Barberán A, Bates ST, Casamayor EO, Fierer N (2012) Using network analysis to explore co-occurrence patterns in soil microbial communities. The ISME journal 6: 343.

41. Faust K, Raes J (2012) Microbial interactions: from networks to models. Nature Reviews Microbiology 10: 538-550.

42. Mendes LW, Kuramae EE, Navarrete AA, Van Veen JA, Tsai SM (2014) Taxonomical and functional microbial community selection in soybean rhizosphere. The ISME journal 8: 1577-1587.

43. Tripathi BM, Song W, Slik J, Sukri RS, Jaafar S, Dong K, Adams JM (2016) Distinctive Tropical Forest Variants Have Unique Soil Microbial Communities, But Not Always Low Microbial Diversity. Frontiers in microbiology 7.

44. Mendes LW, Tsai SM, Navarrete AA, De Hollander M, van Veen JA, Kuramae EE (2015) Soil-borne microbiome: linking diversity to function. Microbial ecology 70 : 255-265.

45. Hasan DSNAbPA, Ratnayake U, Shams S (2016) Evaluation of rainfall and temperature trends in Brunei Darussalam. AIP Conference Proceedings, vol. 1705. AIP Publishing, pp. 020034.

46. Sukri RS, Wahab RA, Salim KA, Burslem DF (2012) Habitat associations and community structure of dipterocarps in response to environment and soil conditions in Brunei Darussalam, Northwest Borneo. Biotropica 44: 595-605.

47. Kerfahi D, Park J, Tripathi BM, Singh D, Porazinska DL, Moroenyane I, Adams JM (2017) Molecular methods reveal controls on nematode community structure and unexpectedly high nematode diversity, in Svalbard high Arctic tundra. Polar Biology 40: 765-776.

48. van Kerckvoorde A, Trappeniers K, Nijs I, Beyens L (2000) Terrestrial soil diatom assemblages from different vegetation types in Zackenberg (Northeast Greenland). Polar Biology 23: 392-400.

49. Mernild SH, Hasholt B, Liston GE (2008) Climatic control on river discharge simulations, Zackenberg River drainage basin, northeast Greenland. Hydrological Processes 22: 1932-1948. 
50. Westermann S, Elberling B, Højlund Pedersen S, Stendel M, Hansen BU, Liston GE (2015) Future permafrost conditions along environmental gradients in Zackenberg, Greenland. The Cryosphere 9: 719-735.

51. Zhu X, Day AC, Carmichael TJ, Tallman RF (2014) Temporal variation in a population biomass index for Cambridge Bay Arctic Char, Salvelinus alpinus (L.), in relation to large-scale climate variables. Canadian Science Advisory Secretariat (CSAS)

52. Meyer F, Paarmann D, D'Souza M, Olson R, Glass EM, Kubal M, Paczian T, Rodriguez A, Stevens R, Wilke A (2008) The metagenomics RAST server-a public resource for the automatic phylogenetic and functional analysis of metagenomes. BMC bioinformatics 9: 386.

53. Oksanen J, Kindt R, Legendre P, O’Hara B, Stevens MHH, Oksanen MJ, Suggests M (2007) The vegan package. Community ecology package 10: 631-637.

54. Wilke A, Gerlach W, Harrison T, Paczian T, Trimble WL, Meyer F (2016) MG-RAST Manual for version 4, revision.

55. Aziz RK, Bartels D, Best AA, DeJongh M, Disz T, Edwards RA, Formsma K, Gerdes S, Glass EM, Kubal M, Meyer F, Olsen GJ, Olson R, Osterman AL, Overbeek RA, McNeil LK, Paarmann D, Paczian T, Parrello B, Pusch GD, Reich C, Stevens R, Vassieva O, Vonstein V, Wilke A, Zagnitko O (2008) The RAST Server: Rapid Annotations using Subsystems Technology. BMC Genomics 9: 75. doi: 10.1186/14712164-9-75

56. Choi S, Song H, Tripathi BM, Kerfahi D, Kim H, Adams JM (2017) Effect of experimental soil disturbance and recovery on structure and function of soil community: a metagenomic and metagenetic approach. Scientific Reports 7.

57. Urbanová M, Šnajdr J, Baldrian P (2015) Composition of fungal and bacterial communities in forest litter and soil is largely determined by dominant trees. Soil Biology and Biochemistry 84: 53-64.

58. Hirsch P, Gallikowski CA, Siebert J, Peissl K, Kroppenstedt R, Schumann P, Stackebrandt E, Anderson R (2004) Deinococcus frigens sp. nov., Deinococcus saxicola sp. nov., and Deinococcus marmoris sp. nov., low temperature and draught-tolerating, UV-resistant bacteria from continental Antarctica. Systematic and applied microbiology 27: 636-645.

59. Omelchenko MV, Wolf YI, Gaidamakova EK, Matrosova VY, Vasilenko A, Zhai M, Daly MJ, Koonin EV, Makarova KS (2005) Comparative genomics of Thermus 
thermophilus and Deinococcus radiodurans: divergent routes of adaptation to thermophily and radiation resistance. BMC Evolutionary Biology 5: 57.

60. Fierer N, Jackson RB (2006) The diversity and biogeography of soil bacterial communities. Proceedings of the National Academy of Sciences of the United States of America 103: 626-631.

61. Sharma C, Suyal S, Gairola S, Ghildiyal S (2009) Species richness and diversity along an altitudinal gradient in moist temperate forest of Garhwal Himalaya. Journal of American Science 5: 119-128.

62. Pala NA, Mathur M, Iqbal K, Negi A, Shukla G, Chakravarty S (2017) Community dynamics: Competition and facilitation studies of tree species in temperate forests of the Indian Himalaya. Indian Journal of Ecology 44: 279-288.

63. Gopalakrishna SP, Kaonga ML, Somashekar RK, Suresh HS, Suresh R (2015) Tree diversity in the tropical dry forest of Bannerghatta National Park in Eastern Ghats, Southern India. European Journal of Ecology 1: 12-27.

64. Baboo B, Sagar R, Bargali S, Verma H (2017) Tree species composition, regeneration and diversity of an Indian dry tropical forest protected area. Tropical Ecology 58: 409423.

65. Upadhaya K, Thapa N, Barik SK (2015) Tree diversity and biomass of tropical forests under two management regimes in Garo hills of north-eastern India. Tropical Ecology 56: $257-268$.

66. Lauber CL, Strickland MS, Bradford MA, Fierer N (2008) The influence of soil properties on the structure of bacterial and fungal communities across land-use types. Soil Biology and Biochemistry 40: 2407-2415.

67. Tripathi BM, Kim M, Lai-Hoe A, Shukor NA, Rahim RA, Go R, Adams JM (2013) pH dominates variation in tropical soil archaeal diversity and community structure. FEMS microbiology ecology 86: 303-311.

68. Willig MR, Kaufman D, Stevens R (2003) Latitudinal gradients of biodiversity: pattern, process, scale, and synthesis. Annual Review of Ecology, Evolution, and Systematics 34: 273-309.

69. Yergeau E, Newsham KK, Pearce DA, Kowalchuk GA (2007) Patterns of bacterial diversity across a range of Antarctic terrestrial habitats. Environmental microbiology 9: 2670-2682. 
70. Neufeld JD, Mohn WW (2005) Unexpectedly high bacterial diversity in arctic tundra relative to boreal forest soils, revealed by serial analysis of ribosomal sequence tags. Applied and Environmental Microbiology 71: 5710-5718.

71. Tripathi BM, Kim M, Singh D, Lee-Cruz L, Lai-Hoe A, Ainuddin A, Go R, Rahim RA, Husni M, Chun J (2012) Tropical soil bacterial communities in Malaysia: pH dominates in the equatorial tropics too. Microbial ecology 64: 474-484.

72. Morita R (1992) Low-temperature environments. Encyclopedia of microbiology 2: 625-637.

73. Marchant R, Banat IM, Rahman TJ, Berzano M (2002) The frequency and characteristics of highly thermophilic bacteria in cool soil environments. Environmental Microbiology 4: 595-602.

74. Vos M, Wolf AB, Jennings SJ, Kowalchuk GA (2013) Micro-scale determinants of bacterial diversity in soil. FEMS microbiology reviews 37: 936-954.

75. Csonka LN (1989) Physiological and genetic responses of bacteria to osmotic stress. Microbiological reviews 53: 121-147.

76. Beales N (2004) Adaptation of microorganisms to cold temperatures, weak acid preservatives, low $\mathrm{pH}$, and osmotic stress: a review. Comprehensive reviews in food science and food safety 3: 1-20.

77. Turchin P, Taylor AD (1992) Complex dynamics in ecological time series. Ecology 73: 289-305.

78. Grandy AS, Neff JC (2008) Molecular C dynamics downstream: the biochemical decomposition sequence and its impact on soil organic matter structure and function. Science of the Total Environment 404: 297-307.

79. Adams JM, Rehill B, Zhang Y, Gower J (2009) A test of the latitudinal defense hypothesis: herbivory, tannins and total phenolics in four North American tree species. Ecological Research 24: 697-704.

80. Adachi M, Bekku YS, Rashidah W, Okuda T, Koizumi H (2006) Differences in soil respiration between different tropical ecosystems. Applied soil ecology 34: 258-265.

81. Bekku YS, Nakatsubo T, Kume A, Adachi M, Koizumi H (2003) Effect of warming on the temperature dependence of soil respiration rate in arctic, temperate and tropical soils. Applied soil ecology 22: 205-210. 
82. Nadelhoffer KJ, Shaver GR, Giblin A, Rastetter EB (1997) Potential impacts of climate change on nutrient cycling, decomposition, and productivity in arctic ecosystemsGlobal Change and Arctic Terrestrial Ecosystems. Springer, pp. 349-364

83. Møller AP (1998) Evidence of larger impact of parasites on hosts in the tropics: investment in immune function within and outside the tropics. Oikos: 265-270.

84. Hannula SE, Morriën E, de Hollander M, van der Putten WH, van Veen JA, de Boer W (2017) Shifts in rhizosphere fungal community during secondary succession following abandonment from agriculture. The Isme Journal 11: 2294. doi: 10.1038/ismej.2017.90

\section{https://www.nature.com/articles/ismej201790\#supplementary-information}

85. Morriën E, Hannula SE, Snoek LB, Helmsing NR, Zweers H, de Hollander M, Soto RL, Bouffaud M-L, Buée M, Dimmers W, Duyts H, Geisen S, Girlanda M, Griffiths RI, Jørgensen H-B, Jensen J, Plassart P, Redecker D, Schmelz RM, Schmidt O, Thomson BC, Tisserant E, Uroz S, Winding A, Bailey MJ, Bonkowski M, Faber JH, Martin F, Lemanceau P, de Boer W, van Veen JA, van der Putten WH (2017) Soil networks become more connected and take up more carbon as nature restoration progresses. Nature Communications 8: 14349. doi: 10.1038/ncomms14349

https://www.nature.com/articles/ncomms14349\#supplementary-information

86. van der Meij WM, Temme AJ, de Kleijn CM, Heuvelink GB (2016) Arctic soil development on a series of marine terraces on central Spitsbergen, Svalbard: a combined geochronology, fieldwork and modelling approach. Soil 2: 221.

87. Hodkinson ID, Coulson SJ, Webb NR (2003) Community assembly along proglacial chronosequences in the high Arctic: vegetation and soil development in north-west Svalbard. Journal of Ecology 91: 651-663.

88. Weintraub MN, Schimel JP (2003) Interactions between carbon and nitrogen mineralization and soil organic matter chemistry in arctic tundra soils. Ecosystems 6: 0129-0143.

89. Fierer N (2017) Embracing the unknown: disentangling the complexities of the soil microbiome. Nature reviews Microbiology.

90. Potvin LR, Kane ES, Chimner RA, Kolka RK, Lilleskov EA (2015) Effects of water table position and plant functional group on plant community, aboveground production, and peat properties in a peatland mesocosm experiment (PEATcosm). Plant and soil 387: 277-294. 
91. Teuben A, Verhoef H (1992) Relevance of micro-and mesocosm experiments for studying soil ecosystem processes. Soil Biology and Biochemistry 24: 1179-1183.

92. Verhoef HA (1996) The role of soil microcosms in the study of ecosystem processes. Ecology 77: 685-690. 


\section{Table legends}

Table1 Comparison of relative abundance of the dominant phyla detected in the shotgun matagenomic sequences ${ }^{\mathrm{a}}$.

Table 2 Relative abundance (means \pm SD) of functional gene categories at subsystem level 1 (Subsystems database) in different tropical and polar sites ${ }^{\mathrm{a}}$.

Table 3 Characteristics of network correlations of microbial communities in Brunei and Svalbard sites.

Table 4 Summary of our predictions and our findings.

\section{Figure legends}

Fig. 1 Relative abundance of microbial groups observed in shotgun metagenomic sequences in different tropical and polar sites.

Fig. 2 Relative abundance of the most abundant phyla observed in shotgun metagenomic sequences in different tropical and polar sites.

Fig. 3 Functional abundance of soil microbial communities observed at different tropical and polar sites.

Fig. 4 Non-metric multidimensional scaling (NMDS) ordination based on Bray-Curtis distance of microbial community composition of (a) RefSeq taxonomic profile at class level and (b) Subsystems functional profile at subsystem level 3 of shotgun metagenomic sequences from samples of different high Arctic and tropical sites.

Fig. 5 Taxonomic and functional microbial diversity of soil microbial communities in Svalbard soils, and Brunei and Port Dickson Malaysian soils based on Shannon index.

Fig. 6 Network interactions of soil microbial communities in (a) tropical forest (Brunei) and (b) high Arctic tundra (Svalbard) based on correlation analysis of RefSeq taxonomic profile at class level (red nodes) and Subsystems functional profile at subsystem level 1 (blue nodes). Each edge stands for strong (Spearman's $r>0.9)$ and significant $(P<0.01)$ correlations. The size of each node is proportional to the number of connections.

\section{Supplementary Online Material}

Table S1 Guide to sample sites classification.

Table S2 Total number of base pairs, sequencing reads, predicted protein features, and sequences assigned to different taxa.

Table S3 Variation of relative abundance of the dominant families of bacteria, archaea, eukaryote and viruses in shotgun metagenomic sequences in different tropical and polar sites. 
Fig. S1 Soil sample locations across different tropical and polar sites.

Fig. S2 Relative abundance of CRISPRs genes among different tropical and polar sites.

Fig. S3 Non-metric multidimensional scaling (NMDS) ordination based on Bray-Curtis distance of microbial community composition of (a) RefSeq taxonomic profile at class level and (b) Subsystems functional profile at subsystem level 3 of shotgun metagenomic sequences from Svalbard high Arctic and Brunei tropical. A vector overlay of the significantly correlated environmental variables is shown on the plot.

Fig. S4 Variation of soil $\mathrm{pH}$, total carbon, total nitrogen and available phosphorous among different tropical samples and high Arctic samples.

Fig. S5 Taxonomic microbial diversity of soil microbial families in in Svalbard soils, and Brunei and Port Dickson Malaysian soils based on Shannon index.

Fig. S6 Variations of genes' relative abundances across different sites in tropical and polar study areas. 